\title{
De l'accueil à la rencontre. Mélanges offerts à Jean-Pol Madou, éds. Claude Cavallero
}

\section{Aron Verga}

\section{(2) OpenEdition}

1 Journals

\section{Edizione digitale}

URL: http://journals.openedition.org/studifrancesi/4470

DOI: $10.4000 /$ studifrancesi.4470

ISSN: 2421-5856

\section{Editore}

Rosenberg \& Sellier

\section{Edizione cartacea}

Data di pubblicazione: 1 settembre 2016

Paginazione: $363-364$

ISSN: 0039-2944

\section{Notizia bibliografica digitale}

Aron Verga, « De l'accueil à la rencontre. Mélanges offerts à Jean-Pol Madou, éds. Claude Cavallero», Studi Francesi [Online], 179 (LX | II) | 2016, online dal 01 septembre 2016, consultato il 18 septembre 2020. URL : http://journals.openedition.org/studifrancesi/4470 ; DOl : https://doi.org/10.4000/ studifrancesi.4470

Questo documento è stato generato automaticamente il 18 settembre 2020.

\section{(c)}

Studi Francesi è distribuita con Licenza Creative Commons Attribuzione - Non commerciale - Non opere derivate 4.0 Internazionale. 


\title{
De l'accueil à la rencontre. Mélanges offerts à Jean-Pol Madou, éds. Claude Cavallero
}

\author{
Aron Verga
}

\section{NOTIZIA}

De l'accueil à la rencontre. Mélanges offerts à Jean-Pol Madou, textes réunis par Claude CAVALLERO, Chambéry, Université de Savoie, 2014, «Écriture et représentation», 233 pp.

1 Il volume è composto da tredici articoli e una poesia in omaggio a Jean-Pol Madou, professore di letteratura francese del xx secolo all'Université de Savoie, il cui lavoro di ricerca ha come filo conduttore la passione per il dibattito teorico e l'apertura verso l'Altro, il tutto sotto il segno dell'incontro e del dialogo critico. Come afferma Claude Cavallero si tratta del «témoignage d'une estime sincère pour cet homme humble, ouvert et généreux aux côtés de qui et avec qui nous avons eu le privilège de travailler» (p. 9).

2 In Éloge de l'informe (pp. 65-76), Jean BURGos parte da un aneddoto su Cézanne: il rapido deterioramento delle mele gli impediva di dipingerle alla perfezione, provocando una disorganizzazione, passeggera ma inevitabile, chiamata informe, condizione necessaria affinché emergesse una nuova realtà, simile ma diversa dalla precedente. Per Burgos l'impossibilità della somiglianza perfetta tra le mele reali e quelle dipinte dimostra come la sensazione non cessi di lavorare per distruggere l'immagine mentale. L'autore insiste sulla volontà di cogliere in un determinato momento delle forme, delle linee o dei colori in sé, senza sovrapporre a essi le proprie impressioni o i propri processi di conoscenza: idee presenti già nel trattato cosmologico Sul cielo di Aristotele o nelle Confessioni di Sant'Agostino. Quest'ultimo definiva l'informe non come qualcosa di privo di forma, bensì come una forma insolita per i sensi dell'uomo. Il tema dell'informe lo ritroviamo anche più di recente in Paul Valéry che, nel saggio Degas, danse, dessin, vuole 
restituire alla sensazione la sua natura eclettica e i suoi poteri creativi, definendo l'informe come qualcosa da accettare così com'è: «Ne pas tenter de ramener à tout prix l'informe à des formes connues afin de donner sens au plus tôt» (p. 72).

3 Michael KOHLHAUER, in Le Roman de notre temps. Ou pourquoi il faut lire Michel Houellebecq (pp. 77-102), insiste sull'importanza di leggere Houellebecq. Dopo dei brevi riassunti e analisi dei romanzi dello scrittore francese (fino a La Carte et le territoire del 2010), Kohlhauer parla dell'opera nel suo complesso inserendola nel filone realista/ naturalista, ma con l'aggiunta di numerose pratiche di citazione: dalla parodia al pastiche, all'inserimento di estratti di quotidiani o di pubblicità. L'originalità di Houellebecq starebbe dunque nell'osservare senza moralismi ciò che succede in un'epoca dove l'informe è generalizzato e in cui la frase di Balzac «à chaque œuvre sa forme» ha perso di significato. In conclusione, colui che Kohlhauer definisce un «revenant de la modernité (plutôt que de mai 68)» (p. 102) dovrebbe essere letto poiché illustra al meglio le ambiguità e i paradossi della condizione postmoderna: una società ubriaca di informazioni, di eventi, di soldi, di lavoro o sesso, ma che in fondo si annoia.

4 Portrait de l'écrivain en collectionneur: de Mallarmé à Saint-John Perse (pp. 103-126) di Dominique PETY prende in esame la pratica del collezionismo, trasposta da molti autori del xIX secolo nelle loro opere, legittimando così un fenomeno culturale dell'epoca. Una conferma è stata già fornita dai fratelli Goncourt riguardo ai mutamenti nella scrittura del romanzo grazie all'uso di documenti, dal quale trapela un atteggiamento da collezionisti. L'articolo sottolinea come nel corso del xx secolo permanga una mentalità da collezionista, intesa non più come mero ripiego di una soggettività singola su un passato idealizzato, bensì come un tentativo da parte dell'uomo di ridefinire il suo rapporto con il tempo e con le cose. Attraverso l'analisi della Nausée di Sartre, della Jalousie di Robbe-Grillet, di Le Parti pris des choses di Ponge e di alcune poesie tratte da Éloge e Vents di Saint-John Perse, Pety pone in evidenza come il tema dell'oggetto collezionato sia stato rivalorizzato a partire dall'avvento dei poemi in prosa.

5 In Les Voix de la mémoire. "Mémoires d'une nomade" de Marevna (pp. 143-156), Elisa BORGHINO affronta il tema della presenza femminile in seno alle avanguardie del Novecento, distinguendo alcune tipologie principali: le filantrope, le artiste che si dedicarono anche alla scrittura, le scrittrici e le «touches-à-tout» (p. 144). Per le donne era difficile farsi notare per le proprie abilità artistiche nei movimenti d'avanguardia $\mathrm{e}$, il più delle volte, vivevano all'ombra di compagni, fidanzati o mariti. Di queste artiste, la critica valorizzava per lo più solo le vite straordinarie, lasciando in secondo piano l'interesse per le loro opere. Borghino analizza principalmente Mémoires d'une nomade di Marevna, dove la creazione artistica è al centro di molte riflessioni, in particolare sul rapporto tra donna e arte.

6 Jean-Louis CORNILLE e Annabelle MARIE in L'Indésir (pp. 167-178) ipotizzano la possibilità di spostare l'attenzione degli studi post-coloniali dal «Black Atlantic» all'Oceano Indiano francofono, grazie anche agli autori mauritani presi in considerazione in questo articolo, ovvero Ananda Devi, Natasha Appanah e Amal Sewtohul. I due studiosi sottolineano sovente come nei testi esaminati non vi sia alcuna allusione all'epoca coloniale. Per esempio, Indian Tango della Devi è un racconto di viaggio, però non parla di immigrazione, di esilio e, solo a malapena, di identità. Si tratta di una ricerca delle origini indirizzata verso Oriente, non più verso Occidente.

7 In Les Chemins de clarté de Lorand Gaspar (pp. 179-190) Claude CAVALLERo esamina il lavoro di questo chirurgo poeta, in cui il lessico della luce si impone sin dalla prima raccolta, 
Le Quatrième état de la matière (1966). Cavallero evidenzia come quest'opera poetica possegga «l'insatiable besoin de faire la lumière sur l'inconnu qui règne en nous et autour de nous» (p. 179).

8 Kathleen GYSSELS sottolinea in "Champs magnétiques": Damas et Glissant en ba[l]ladeurs $d u$ "Black Atlantic" (pp. 191-220) come Léon-Gontran Damas non abbia ricevuto le stesse onorificenze di Aimé Césaire, poiché autore di un'opera ridotta e poeta minore (infatti si espresse in un francese più semplice, con frasi meno articolate, e in una poesia meno sofisticata). Inoltre viene sottolineato come Damas sia stato escluso dalle antologie soprattutto per non aver più pubblicato dopo il 1966.

9 I restanti articoli sono di: Florence CLERC (L'Ambivalence comique dans la tradition picaresque, pp. 21-36); Barbara MEAZZI (Les Amours futuristes: une tentative échouée de séduction, pp. 37-50) che del Futurismo sottolinea, al femminile, l'ambivalenza della dimensione seduttiva; Christian BERG (Maeterlinck et l'anneau de Polycrate, pp. 51-64) che insiste su come Maeterlinck fosse posseduto da una «inquiétude du bonheur» (p. 63) dopo che la vita aveva soddisfatto le sue attese; Paul PELCKMAns (De l'esprit public aux raisons du cour. À propos d'une nouvelle oubliée de Florian, pp. 127-142) che sottolinea come le Fables e le Nouvelles di Florian fossero tra le migliori del XVIII secolo; Jean-Paul GAVARDPERRET (Le Mythe du genre, l'inversion des focales de Michel Journiac, pp. 157-166) che analizza alcune opere di Michel Journiac, artista visivo, il primo a mettere in discussione la differenziazione sessuale dei ruoli, genitoriali e di genere; Pascal BOUVIER (Le Visage: du phénoménisme à la phénoménologie, pp. 221-230) che indaga dal punto di vista fenomenologico l'importanza del volto in filosofia, esaminando due aspetti: la possibilità di leggere il volto, ovvero la fisiognomica, e la manifestazione dell'alterità del volto. Il volume è chiuso da una poesia di Claude CAVALLERO, «Était-ce vraiment le bout du monde» (p. 233). 